\title{
STUDY ON THE GENETIC PREDISPOSITION TO BREAST CANCER AND THE DNA DAMAGE RESPONSE AT TELOMERES AND IN CELLULAR SENESCENCE
}

\author{
FRANCESCA ROSSIELLO $\left(^{*}\right)$, et al. ${ }^{\#}$ \\ Nota presentata dal s.c. Andrea Mattevi \\ (Adunanza del 24 novembre 2016)
}

\begin{abstract}
SUNTO. - Le mutazioni germinali nella sequenza codificante di alcuni geni, in particolare BRCA1 e BRCA2, conferiscono un elevato rischio di insorgenza del tumore alla mammella. Tuttavia circa il $70 \%$ dei casi non sono associabili a nessuna mutazione conosciuta. Mediante uno screening per sequenziamento a partire da sangue periferico di pazienti e controlli sani, abbiamo identificato alcune mutazioni germinali non descritte in precedenza nella regione non codificante 3' UTR del gene BRCA1. Queste mutazioni possono causare un'alterazione dell'espressione genica, e possono quindi essere utili per predire, con una maggiore accuratezza, la predisposizione al tumore familiare alla mammella. Successivamente, per comprendere i meccanismi di invecchiamento cellulare in cellule non proliferanti abbiamo studiato il segnale di DNA damage response (DDR) persistente nelle cellule senescenti, sia in colture cellulari che in tessuti animali, e abbiamo scoperto che questi segnali localizzano principalmente ai telomeri, indipendentemente dalla loro lunghezza. L'accumulo di danno al DNA telomerico, dovuto all'inibizione dei meccanismi di riparo, se da una parte causa l'invecchiamento
\end{abstract}

(*) IFOM-The FIRC Institute of Molecular Oncology, Milan, Italia.

E-mail: francesca.rossiello@ifom.eu

(\#) La nota è il risultato di un lavoro di ricerca condotto in collaborazione con: B.L. Brewster, J.D. French, S.L. Edwards, M. Wong, A. Wronski, P. Whiley, N. Waddell, X. Chen, B. Bove, KConFAB, J.L. Hopper, E.M. John, I. Andrulis, M. Daly, S. Volorio, L. Bernard, B. Peissel, S. Manoukian, M. Barile, S. Pizzamiglio, P. Verderio, A.B. Spurdle, P. Radice, A.K. Godwin, M.C. Southey, M.A. Brown, P. Peterlongo, M. Fumagalli, M. Clerici, S. Barozzi, D. Cittaro, J.M. Kaplunov, G. Bucci, M. Dobreva, V. Matti, C.M. Beausejour, U. Herbig, M.P. Longhese, C. Mondello, F. d'Adda di Fagagna. 
cellulare e dell'individuo, è un importante meccanismo anti tumorale, in quanto previene l'iperproliferazione delle cellule nelle fasi iniziali di trasformazione neoplastica.

$* * *$

ABSTRACT. - Germ line mutations in the coding sequence of some genes, mainly BRCA1 and BRCA2, confer a high risk of developing breast cancer. However, about $70 \%$ of tumors cases are not associated with any known mutation. By screening by sequencing peripheral blood of patients and healthy controls, we identified some previously unknown germline mutations in the 3 'UTR non-coding region of the BRCA1 gene. These mutations can modify gene expression, and can therefore be useful to predict, with greater accuracy, familiar breast cancer predisposition. Subsequently, to understand the mechanisms of aging in non-proliferating cells we studied the persistent DNA damage response (DDR) signal in senescent cells, both in cell cultures and in animal tissues, and we found that these signals mainly localize to telomeres, independently from their length. The accumulation of damage at the telomeric DNA, due to the inhibition of the repair mechanisms, causes cellular and individual aging, but it is also an important anti-tumor mechanism, as it prevents the uncontrolled cell growth during the early stages of neoplastic transformation.

During my master thesis internship, I participated to a project focused on understanding better the genetic predisposition to familiar breast cancer [Ch. 1].

Germline mutations with higher penetration, which confer a high risk of developing breast cancer, are located in the BRCA1 and BRCA2 coding region. Other mutations in other genes that determine a moderate risk of cancer are also known. However, about $70 \%$ of breast cancers are not associated with any known mutations.

We performed a screening by sequencing to identify germline mutations in the non-coding region 3' UTR of the BRCA1 gene, starting from peripheral blood of female breast cancer patients who had no mutations in the coding region of BRCA1 and 2 genes. Healthy donors were used for the control group. As a result of this screening, we have identified new variants not previously described, which were detected only in patients. Mutations in the 3' UTR regions can cause gene expression alteration by forming new miRNA interaction sites. By in silico studies, we have shown that some of these variants produce new sites for some miRNAs. BRCA1 acts as an oncosuppressor, so a reduction in its expression can cause a greater cancer incidence. To experimentally validate the hypothesis that these novel identified variants could determine an altered expression of the BRCA1 gene, we performed luciferase expression experiments, in which luciferase gene was cloned upstream of the 3' UTR 
region, containing the mutation under investigation. We have therefore verified that some of these variants modify the expression of luciferase, if co-expressed with the related miRNA.

These results indicate that a more in-depth study of BRCA1 gene mutations in the 3'UTR region may be useful in predicting with greater accuracy the predisposition to familial breast cancer.

During my PhD internship, I moved to the field of DNA damage and telomeres [Ch. 2].

Replicative senescence, caused by progressive telomere shortening, has been deeply studied in the past fifty years. However it was not yet clear which molecular events regulated the aging of non-proliferating cells.

Cells have several DNA repair mechanisms that ensure the maintenance of the integrity of genetic information. In this study, we found that when telomeric DNA is damaged, it cannot be fixed because the telomeric protein TRF2 inhibits cellular repair mechanisms. This phenomenon causes a persistent DNA damage response (DDR) signal, which activates the senescence program, regardless of the length of the telomeres. To confirm these in vitro results, we observed an accumulation of DDR markers in aged baboons, in tissues made of non-proliferating cells, such as liver and hippocampus. This discovery has an important implication in the oncology field. In fact, a study in collaboration with some members of our group (Suram et al., Embo Journal, 2012) showed that hyper-proliferation associated with the expression of an oncogene in the early stages of tumorigenesis causes replicative stress, leading to accumulation of telomeric damage, persistent DDR and activation and cellular senescence. Only when tumor cells accumulate further mutations, which cause the DDR to be deactivated at telomeres, tumor progression may take place.

These data suggest that the inhibition of repair mechanism at telomeres, despite causing cellular and organismal aging, is an essential anti-tumor mechanism.

Finally I was involved in another project, aimed to investigate more deeply the mechanisms regulating cellular senescence [Ch. 3].

Cellular senescence is a permanent cell cycle arrest characterized by persistent DDR activation. However, some reports suggested that DDR activation is a feature only of early cellular senescence that is then lost with time. This challenged the hypothesis of a causal relationship between DDR activation and cellular senescence.

We examined whether the DDR of telomeres in the senescent 
cells was really persistent or whether it was activated at first and then turned off.

To better understand the differences in the experimental conditions that led to opposite conclusions, we analysed replicative senescence and ionizing radiation-induced senescence in different cell lines. We observed how the loss of DDR markers, which leaded to a temporary activation of DDR, correlated with the inability of the cell line to survive in culture for weeks or months. The death of the most damaged cells therefore caused a bias in the interpretation of the results. By analysing instead a cell line that was very resistant to the stress caused by in vitro culture, we have observed how DDR markers are constantly activated for weeks or months - the entire duration of the experiments. In support of these observations, human skin fibroblasts from ultra-centenarians donors, and cultured up to three years in vitro, still showed the activation of the DDR markers, indicating that also in vivo activated senescence is constantly supported by persistent DDR.

We concluded that different types of senescence (replicative, ionizing radiation-induced and in vivo activated) are associated with a constant DDR activation that acts as a trigger for the maintenance of cellular senescence program.

\section{IDENTIFICATION OF FIFTEEN NOVEL GERMLINE VARIANTS IN THE BRCA1 3'UTR REVEALS A VARIANT IN A BREAST CANCER CASE THAT INTRODUCES A FUNCTIONAL MIR-103 TARGET SITE ${ }^{1}$}

\section{Introduction}

Germline mutations with higher penetration, which confer a high risk of developing breast cancer, are located in the BRCA1 and BRCA2 coding region. Other mutations in other genes that determine a moderate risk of cancer are also known. However, about $70 \%$ of breast cancers are not associated with any known mutations.

1 Brewster BL*, Rossiello F*, French JD, Edwards SL, Wong M, Wronski A, Whiley P, Waddell N, Chen X, Bove B; kConFab, Hopper JL, John EM, Andrulis I, Daly M, Volorio S, Bernard L, Peissel B, Manoukian S, Barile M, Pizzamiglio S, Verderio P, Spurdle AB, Radice P, Godwin AK, Southey MC, Brown MA, Peterlongo P. Human Mutation, 2012. *Equal contribution. 
Results

We performed a screening by sequencing to identify germline mutations in the non-coding region 3' UTR of the BRCA1 gene, starting from peripheral blood of female breast cancer patients who had no mutations in the coding region of BRCA1 and 2 genes. Healthy donors were used for the control group. As a result of this screening, we have identified new variants not previously described, which were detected only in patients. Mutations in the 3' UTR regions can cause gene expression alteration by forming new miRNA interaction sites. By in silico studies, we have shown that some of these variants produce new sites for some miRNAs. BRCA1 acts as an oncosuppressor, so a reduction in its expression can cause a greater cancer incidence. To experimentally validate the hypothesis that these novel identified variants could determine an altered expression of the BRCA1 gene, we performed luciferase expression experiments, in which luciferase gene was cloned upstream of the 3' UTR region, containing the mutation under investigation. We have therefore verified that some of these variants modify the expression of luciferase, if co-expressed with the related miRNA.

\section{Conclusions}

These results indicate that a more in-depth study of BRCA1 gene mutations in the 3'UTR region may be useful in predicting with greater accuracy the predisposition to familial breast cancer.

\section{Telomeric DNA DAMAgE IS IRREPARABLE AND CAUSES PERSISTENT DNA-DAMAGE-RESPONSE ACTIVATION ${ }^{2}$}

\section{Introduction}

Replicative senescence, caused by progressive telomere shortening, has been deeply studied in the past fifty years. However it was not

2 Fumagalli $\mathrm{M}^{*}$, Rossiello $\mathrm{F}^{*}$, Clerici M, Barozzi S, Cittaro D, Kaplunov JM, Bucci G, Dobreva M, Matti V, Beausejour CM, Herbig U, Longhese MP, d'Adda di Fagagna F. Nature Cell Biology, 2012. *Equal contribution. 
yet clear which molecular events regulated the aging of non-proliferating cells.

Results

Cells have several DNA repair mechanisms that ensure the maintenance of the integrity of genetic information. In this study, we found that when telomeric DNA is damaged, it cannot be fixed because the telomeric protein TRF2 inhibits cellular repair mechanisms. This phenomenon causes a persistent DNA damage response (DDR) signal, which activates the senescence program, regardless of the length of the telomeres. To confirm these in vitro results, we observed an accumulation of DDR markers in aged baboons, in tissues made of non-proliferating cells, such as liver and hippocampus. This discovery has an important implication in the oncology field. In fact, a study in collaboration with some members of our group (Suram et al., Embo Journal, 2012) showed that hyper-proliferation associated with the expression of an oncogene in the early stages of tumorigenesis causes replicative stress, leading to accumulation of telomeric damage, persistent DDR and activation and cellular senescence. Only when tumor cells accumulate further mutations, which cause the DDR to be deactivated at telomeres, tumor progression may take place.

\section{Conclusions}

These data suggest that the inhibition of repair mechanism at telomeres, despite causing cellular and organismal aging, is an essential anti-tumor mechanism.

\section{STABLE CELLULAR SENESCENCE IS ASSOCIATED WITH PERSISTENT DDR ACTIVATION ${ }^{3}$}

\section{Introduction}

Cellular senescence is a permanent cell cycle arrest characterized by persistent DDR activation. However, some reports suggested that

3 Fumagalli M, Rossiello F, Mondello C, d'Adda di Fagagna F. PLoS One, 2014. 
DDR activation is a feature only of early cellular senescence that is then lost with time. This challenged the hypothesis of a causal relationship between DDR activation and cellular senescence.

Results

We examined whether the DDR of telomeres in the senescent cells was really persistent or whether it was activated at first and then turned off.

To better understand the differences in the experimental conditions that led to opposite conclusions, we analysed replicative senescence and ionizing radiation-induced senescence in different cell lines. We observed how the loss of DDR markers, which leaded to a temporary activation of DDR, correlated with the inability of the cell line to survive in culture for weeks or months. The death of the most damaged cells therefore caused a bias in the interpretation of the results. By analysing instead a cell line that was very resistant to the stress caused by in vitro culture, we have observed how DDR markers are constantly activated for weeks or months - the entire duration of the experiments. In support of these observations, human skin fibroblasts from ultracentenarians donors, and cultured up to three years in vitro, still showed the activation of the DDR markers, indicating that also in vivo activated senescence is constantly supported by persistent DDR.

\section{Conclusions}

We concluded that different types of senescence (replicative, ionizing radiation-induced and in vivo activated) are associated with a constant DDR activation that acts as a trigger for the maintenance of cellular senescence program. 
